\title{
Who gets the Vaccine First? An Analysis of Underlying Debates and Imperatives on Future COVID-19 Vaccine
}

\author{
Felix Kwabena Donkor* and Kevin Mearns \\ College of Agriculture and Environmental Sciences (CAES), University of South Africa (UNISA), South Africa
}

*Corresponding author: Felix Kwabena Donkor, College of Agriculture and Environmental Sciences (CAES), University of South

Africa (UNISA), South Africa

\begin{tabular}{lll}
\hline ARTICLE INFO & & ABSTRACT \\
\cline { 1 - 1 } $\begin{array}{l}\text { Received: } \\
\text { Published: } \text { 幽 October 02, } 2020\end{array}$ & $\begin{array}{l}\text { Citation: Felix Kwabena Donkor, Kevin Mearns. Who gets the Vaccine First? An Analysis } \\
\text { of Underlying Debates and Imperatives on Future COVID-19 Vaccine. Biomed J Sci \& Tech } \\
\text { Res 31(1)-2020. BJSTR. MS.ID.005059. }\end{array}$ \\
\hline
\end{tabular}

\section{Opinion}

It has become evident that it is not possible to get the vaccine to everyone at the same time, hence the need to develop a guideline that will shape the administering of the vaccine in future [1]. Advisory groups around the world including the World Health Organization (WHO) and the United States (US) National Academies of Sciences, Engineering, and Medicine (NASEM) continue to debate on guidelines for allocating the vaccine [2]. How-ever, a common element in all such guidelines have been the prioritization of healthcare workers and those in front-line jobs. The NASEM guideline indicates that after addressing the needs of health-care workers, groups deemed to be vulnerable in terms of their health should be given priority in administering a vaccine. These embrace elderly individuals and those in congested environments, as well as people with several preexisting illnesses, including acute heart ailments or diabetes, that render them susceptible to more grave COVID-19 infection. The guideline gives priority to those working in critical sectors including public transit, since their work puts them in direct contact with numerous individuals. In addition, people dwelling in congested places are mentioned as requiring priority access.

The guidelines from NASEM in particular is lauded for highlighting the circumstances of minority racial and ethnic groups - which COVID-19 has hit hard - by pointing to the socio-economic factors that render them at increased risks of such infections [3]. On the reverse, the guidelines from the WHO is still in the inception phase and requires further information before its commendations can become actionable, others argue. This opinion piece considers some of the core arguments as to who should be vaccinated first when a COVID-19 vaccine becomes available. The regimen for prioritizing the groups was informed by previous vaccination outreaches in the 2009 H1N1 flu outbreak and 2014-2016 Ebola outbreak in West Africa, informing the benchmarks that guide privileged vaccine accessibility:

I. Level of risk associated with COVID-19 acquisition: individuals with highest susceptibility of being infected with the COVID-19, including frontline workers in medical facilities and those with background health challenges which heightens their dangers of COVID-19 complications and mortality. Older adults living in crowded settings, such as nursing homes, would also be at the front row [1].

II. Level of risk in terms of underlying morbidities and mortalities: this is to address the peculiar needs of those who fall in the category of essential workers as they operate in some of the most critical social sectors that enable it to function. These are the ones that help safeguard the fabric of essential services. This is more so as several of such workers have contracted the COVID-19 virus whilst conducting their work. Furthermore, this category employs individuals with background ailments that moderately heighten the chances of infection. Furthermore, other elderly adults and individuals in aged homes and people working in penitentiaries incarceration centers etc. This also includes kids who have been observed to not demonstrate acute disease symptoms, however, are argued to be key players in community transmissions. 
III. Level of risk associated with grave social consequences: this category embraces young adults and kids together with outstanding essential workers not catered for in phase 2 . This is partly due to the acknowledgement that young adults in 18 to 30 age categories amongst the spreaders of the COVID-19 infection and thus exacerbating the pandemic via asymptomatic and pre-symptomatic transmission. It is anticipated that a vaccine would help limit the chances of them spreading the virus to friends and family.

IV. Level of risk in terms of disease transmission: this is to help address individuals with higher likelihoods of spreading the infection to other people. The virus affects all individuals without discrimination, thus increasing levels of vaccination in the overall public will be of immense benefit as it will hinder the spread of the virus through the population.

In general, the pandemic has presented an opportunity to review vaccine-allocation regimes. Governments hence have the imperative to commence plans as to how to undertake distribution of vaccines effectively and equitably in light of present realities. In the absence of a concise strategy, valuable time will be wasted, and governments might end up taking ad hoc measures that will only be counterproductive in the long run. Moreover, the global community will not be successful in resiling the overall potential of a vaccine [3]. Nevertheless, several countries have in place some form of vaccine-allocation scheme. However, these are aimed at combatting the influenza pandemic and not the novel coronavirus. Thus, the new coronavirus falls under the radar of many vaccineallocation programmed Furthermore, they mostly give priority to children and pregnant women. It is noteworthy that most of the vaccine trials under way do not give such priority to children and pregnant women. Analysis of the co-rovirus infections also indicate that the coronavirus appears to be less lethal to children than influenza is. This may account for the less prioritization of children and pregnant women in most of the ongoing vaccine trials.

Globally, there are over 150 coronavirus vaccines are in development in different phases of development around the world-and there are great aspirations of bringing one to market in record time to help address the prevailing global crisis. This includes ongoing vaccine trials such as those in South Africa piloted developed by the Britain-based Oxford Jen-ner Institute as well as clinical trials of NVX-CoV2373, developed by US biotech company No-vavax [4] as well as ongoing trials in other parts of the globe including Brazil, the United Kingdom, the United States, China, Russia [5]. An interesting aspect of the WHO guideline is that contrary to that of NASEM, the WHO strategy indicates that government leaders should be given early access to future vaccines, although cautioning that people given privileged access in this regard should be "narrowly interpreted to include a very small number of individuals". However, the widespread corruption that has al-ready bedeviled several health systems across the globe make this a controversial and yet contentious matter. Recently in Geneva, the World Health Organization (WHO) chief directorgeneral was questioned about corrupt practices regarding medical safety gear for COVID-19 health workers. In no uncertain terms Tedros Adhanom Ghebreyesus said that corruption which denies health workers of much needed personal protective equipment (PPE) threatened not only their lives but also the lives of their patients suffering from the novel coronavirus $[6,7]$.

Thus, governments and key stakeholders have big decisions to consider. Issues such as vaccine being purchased privately or solely via public channels, including a nation's national health service amongst others. Some also argue that in majority of countries across the world, people can only obtain privileged accessibility to most medicines by purchasing them in private. Nevertheless, the pandemic is presenting a situation similar to a war situation where crucial goods in limited supply need to be rationed [3]. In furtherance of the above discussions on the criteria governing the initially limited doses of the vaccine; deciding who gains privileged access to the vaccine will necessitate balancing different, sometimes competing considerations. Some of the core issues to consider involve limiting the most adverse health impacts of COVID-19, curtailing the rate of transmission, and enabling the economy to return to normalcy. In addition to creating a transparent standard to guide distribution, several practical matters concerning the vaccine introduction will very have to be addressed, such as the price and effectiveness of administering it at the workplace as opposed to other places such as hospitals and clinics.

\section{Conclusion}

After the successful development of a vaccine, the following hurdle will involve its distribution. The global community and key stakeholders need to prepare for this phase now. Even as governments have to take decisions at the state level, it is increasingly clear the need for While governments need to make decisions at a national level, there also needs to be a synchronized global effort. Thus far, wealthy nations have gone ahead to purchase vaccine doses ahead of their completion. Global initiatives to purchase doses for low and middle-income countries are yet to gain traction. However, the rapid international spread of the coronavirus indicates that it is the interest of the global community to ensure the pandemic is effectively contained. The race to beat COVID-19 will be achieved in phases.

\section{References}

1. Ries J (2020) Experts Come Up with Plan for Who Gets the COVID-19 Vaccine First, Healthline, USA

2. Subbaraman N (2020) Who gets a COVID vaccine first? Access plans are taking shape. Nature.

3. Roope L, Clarke P (2020) Who will get the coronavirus vaccine first? We need to plan now, UK.

4. (2020) Medical X Press, South Africa rolls out second coronavirus vaccine trial, Medical Xpress. 
5. Mc Keever A (2020) Dozens of COVID-19 vaccines are in development. Here are the ones to follow, USA.

6. (2020), EWN, WHO CHIEF BRANDS COVID-19 PPE CORRUPTION 'MURDER, WHO, USA.

\section{ISSN: 2574-1241}

DOI: 10.26717/BJSTR.2020.31.005059

Felix Kwabena Donkor. Biomed J Sci \& Tech Res

(C) (P) This work is licensed under Creative

Submission Link: https://biomedres.us/submit-manuscript.php
7. Williams JH, Dawson A (2020) Prioritising access to pandemic influenza vaccine: a review of the ethics literature. BMC Med Ethics 21: 40

$\begin{array}{ll}\text { BIOMEDICAL } & \text { Assets of Publishing with us } \\ \text { RESEARCHES } & \text { - Global archiving of articles } \\ \text { - Immediate, unrestricted online access } \\ \end{array}$

